\title{
青藏高原晴空行星反照率与 地面反照率关系的研究*
}

\author{
祝昌汉 朱福康 \\ （国家气象局气象科学研究院，北京 100081）（国家气象局卫星气象中心,北京 100081）
}

\section{关锥词青藏高原、行星反照率、地面反照率、AVHRR 资料}

地面反照率是数值模拟和地面能量平衡方程中的一个重要参数. 过去, 对于地面反照率 的估计,一般是根据实测资料结合植被特征的土壤类型分布图推算得到的 ${ }^{[1-3]}$, 这种方法往往 会产生代表性和某些类型不确定性的问题. 随着气象卫星的发展, 利用卫星观测资料研究地 表面反照率是比较理想的方法之一.近年, 国内外做了不少工作 ${ }^{[4-7]}$.从卫星观测资料转换为地 面反照率,实质性问题是我们能否合理地处理和建立晴空行星反照率与地面反照率之间关系.

\section{一、物 理 模 型}

晴空行星反照率与地面反照率分别表征晴天无云大气一地球系统和地表面对太阳辐 射 的 反射能力. 图 1 为晴空行星反照率与地面反

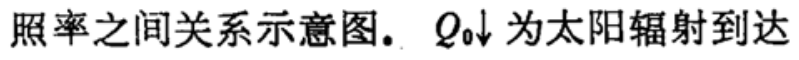
大气层顶的能量; 大气层对太阳辐射的反照 率为 $\alpha_{\Lambda}$; 大气吸收率为 $R$; 地面反照率 为 $\alpha_{g} ;$ 大气对受到地面反射的向上漫射辐 射的 反照率为 $\alpha_{\Lambda}^{*}$.

1. 单次地面反射因 $\alpha_{A}, \alpha_{\Lambda}^{*}$ 以及 $R$ 远小于 $\alpha_{g}{ }^{[8]}$, 故可忽略 $\alpha_{A}, \alpha_{A}^{*}$ 和 $R$ 的高次 项, 得到行星反照率 $\rho$ :

$$
\begin{aligned}
\rho= & \frac{Q_{0} \uparrow}{Q_{0} \downarrow}=\alpha_{\Lambda} \\
& +\left(1-\alpha_{A}-\alpha_{\Lambda}^{*}-2 R\right) \alpha_{\xi} .
\end{aligned}
$$

2. 多次地面反讨 同理，略去 $\alpha_{\Lambda} 、 \alpha_{A}^{*}$

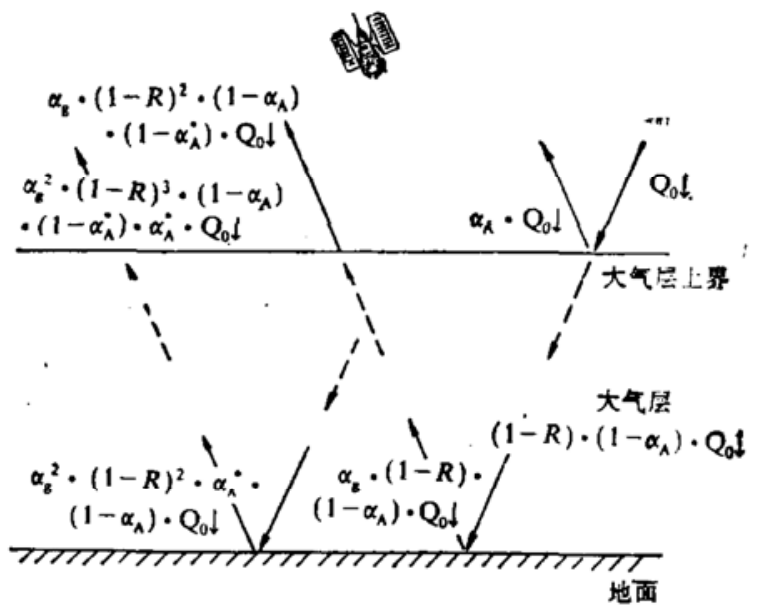

图 1 晴空行星反照率与地面反照率关系示意图

和 $R$ 的高次项, 则得到行星反照率 $\rho$ :

$$
\rho=\alpha_{\Lambda}+\left(1-\alpha_{\Lambda}-\alpha_{\Lambda}^{*}-2 R\right) \alpha_{g}+\alpha_{\Lambda}^{*} \alpha_{g}^{2} .
$$

从物理意义看, 行星反照率并不是地面和大气反照率简单相加. 当仅考虑一次地面反射 时, 行星反照率为地面反照率的一次函数,其结果与 Chen 等 ${ }^{[4]}$ 和 Zhong 等 ${ }^{(6)}$ 导出关系相同. 若考虑大气与地面反照率之间的多次反射时, 行星反照率与地面反照率之间呈抛物线的关系.

本文 1990 年 2 月 5 日收到. 1990 年4月 23 日收到修改稿.

* 国家自然科学基金资助项目.

第 20 期 


\section{二、资料 处理}

行星反照率与地面反照率均随太阳高度角而变化. 为了消除太阳高度角的影响, 我们采 用同步观测的方法,即取极轨卫星通过观测点时刻的地面反照率与之匹配.

地面反照率取自 1986 年 6 月 8 日至 7 月 15 日中美青藏高原联合气象考察中拉萨和那曲 两个地面辐射站资料. 探头的波长分别为 $0.3-2.0 \mu \mathrm{m} ; 0.7-2.0 \mu \mathrm{m}$ 以及 $2.0-50.0 \mu \mathrm{m}$. 观测 地点的下垫面类型为高原农田 (拉萨, 海拔高度 $3680 \mathrm{~m}$ ) 和高原草地 (那曲, 海拔高度 $4500 \mathrm{~m}$ ).

卫星资料是利用中美联合考察同期的 NOAA-9 卫星的 GAC (Global Area Coverage) 资料 ${ }^{(3)}$, 它是一种压缩的 AVHRR 资料. 探测波段有 5 个通道，本文用的是第 1 通道(可见光 被段, $0.58-0.68 \mu \mathrm{m}$ ) 和第 2 通道(近红外波段, $0.73-1.1 \mu \mathrm{m}$ ) 资料. 空间分辨率为 $4 \mathrm{~km}$.

由于地面测点反照率代表性及卫星运行轨道漂移和传感器取样等原因, 难精确确定地面 制点对应的卫星资料参数. 另外，消除云的“污染”也是下垫面反照率反演中一个重要 的问

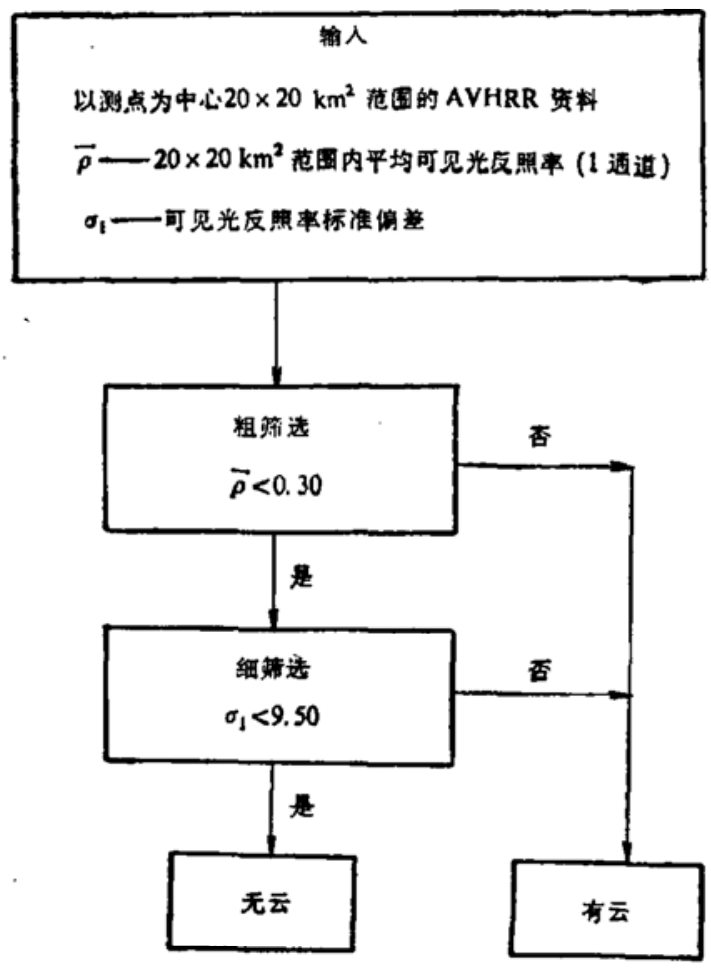

图 2 根据 AVHRR 资料对测点上空云篅 选流程示意图
题.

图 2 是根据 AVHRR 资料处理上述两个 问题的流程示意图. 首先逐日输人以地面判点 为中心 $20 \times 20 \mathrm{~km}^{2}$ 范围内可见光滤过反照率 数据, 并对它求出平均值 $\bar{\rho}$. 我们把平均可见 光滤过反照率 $\bar{\rho}-0.30$ 定为有云的粗管选“阀 值”. 粗笁选掉的主要是大面积的层状云系或 较强的积雨云. 6-7 月份高原上的主要 云系 为对流云系, 特别是中午和下午主要是晴天积 云. 因此, 可以把落人 $20 \times 20 \mathrm{~km}^{2}$ 范围内可见 光滤过反照率的离散程度作为腈天积云多少的 判据. 经调试,把 $20 \times 20 \mathrm{~km}^{2}$ 范围内可见光滤 过反照率标准差 $\sigma_{1}<9.50$ 作为细篮选“润值”. 通过粗、细篮选后, 得 26 天数据, 与地面测站 14 时云量实测值相比, 大多为低云量小于 4 成的 晴天. 最后, 根据 NOAA-9 卫星过境时刻查出 地面测站相对应的地面反照率.NOAA-9 极轨 卫星星下点通过观测点时间大约 是 14:0015:00(地方时)之间,因此这种关系只是反映了

此时段太阳高度角下的经验关系. 据文献 [12], 对于中纬度地区可近似认为代表日平均值.

\section{三、试 验 结 果}

我们首先利用大气层上界太阳光谱分布的权重系数计算出宽带行星反照率 $\rho_{\mathrm{b}}$ :

$$
\rho_{b}=\left(E_{1} \times \rho_{1}+E_{2} \times \rho_{2}\right) / E_{b},
$$

其中 $E_{1} 、 E_{2}$ 和 $E_{\mathrm{b}}$ 分别为日地平均距离时, 大气层上界 $0.58-0.68,0.73-1.10$ 和 $0.58-1.10$ $\boldsymbol{\mu} \mathrm{m}$ 太阳光谱段的能量 ${ }^{[10]}$, 代人即得

$$
\rho_{\mathrm{b}}=0.2820 \rho_{1}+0.6081 \rho_{2}
$$


此公式与 Gutman ${ }^{[11,12]}$ 所使用的宽带行星反 照率公式基本相似.

图 3 为根据 (4) 式计算出的宽带行星反 照率与地面测站相应时刻的总反照率相关分 布图.

1. 单次地面反射按(1)式导出的 次线性关系, 宽带行星反照率与地面反照率 可拟合成

$$
\rho_{\mathrm{b}}=0.045+0.742 \alpha_{\mathrm{g}},
$$

其相关系数为 0.54 , 拟合均方根误差 (RMSE) 为 0.0149 , 拟合相对误差为 $5.54 \%$.

表 1 是本文 (5) 式回归系数与文献中各 回归系数的比较. 由表可知, 本文计算结果 与文献 [6] 的计算比较一致. 由于 $a$ 可以看 作没有地面反射情况下的大气反射辐射的一 个参数, 所以对于平均海拔高度为 $4000 \mathrm{~m}$ 的

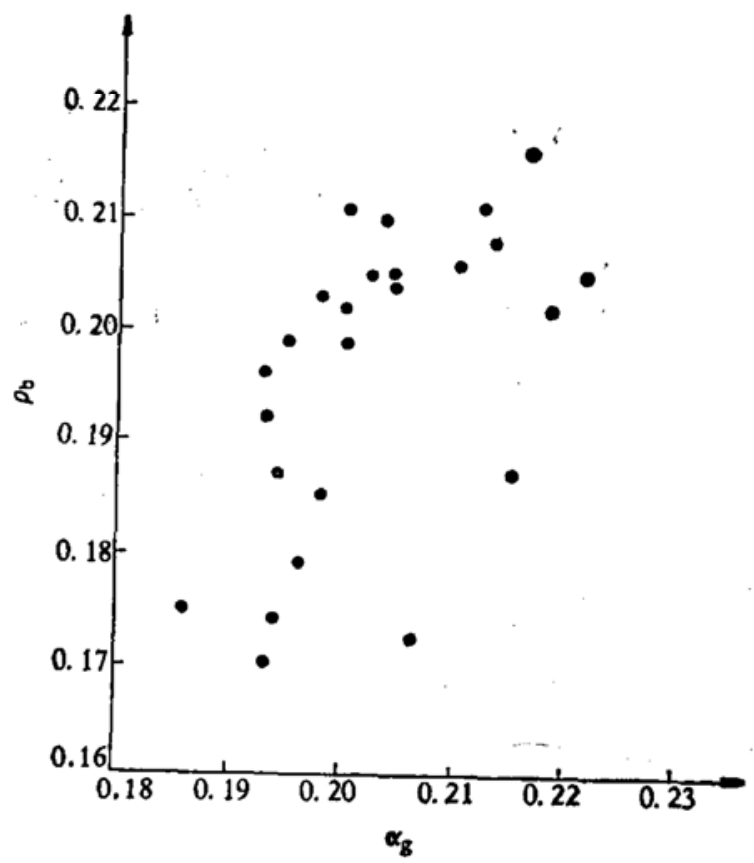

图 3 宽带行星反照率与地面总反照率相关分布图 青藏高原,其 $a$ 值为整个纬圈平均拟合值 ${ }^{[9]}$ 的一半左右是合理的.

2. 多次地面反射当考虑地面与大气多次反射时, 可按(2)式拟合. 拟合时根据上述 讨论, 对 (2)式增添一个下边界条件, 即 $\alpha_{\mathrm{g}}=0$ 时 $\rho_{\mathrm{b}}=0.045$, 则求得

$$
\rho_{\mathrm{b}}=0.045+0.5650 \alpha_{\mathrm{g}}+0.8822 \alpha_{\mathrm{g}}^{2} \text {, }
$$

其相关系数为 0.927 , 拟合均方根误差为 0.0122 , 拟合相对误差为 $5.29 \%$.

\begin{tabular}{|c|c|c|c|c|}
\hline & a & $\mathrm{b}$ & 范 & 围 \\
\hline 本文(5)式 & 0.045 & 0.742 & 青藏高原 & \\
\hline Zhong et al. ${ }^{[6]}$ & 0.05 & 0.8 & 青藏高原 & \\
\hline Preuss et al.t' & 0.087 & 0.59 & $20^{\circ}-40^{\circ} \mathrm{N}$ & 亚热带大陆 \\
\hline
\end{tabular}

表 1 行星反照率与地面反照率回归方程参数比较

拉萨、那曲两测点的平均地面反照率 $\bar{\alpha}_{\mathrm{g}}=0.195$, 代人 (6) 式后, 可大致估计各项在行星 反照率中的贡献. 地面反照率的一次项表示地面反射以及大气透射的能力, 在青藏高原地区约 占行星反照率的 $58 \%$, 青藏高原大气反照率为 $24 \%$,多次散射而产生向上返回辐射为 $18 \%$.

\section{参考文献}

[1] Barry, R. G. et al., Quart. J. Roy. Met. Soc., 92(19 66), 543-548.

[2] 谢贤群, 青藏高原气象科学实验文集(二), 科学出版社, 1984,17-23.

[3] 像治安、翁笉鸣,南京气象学院学振, 10(1987),189-200.

[ 4] Chen, T. S. et al., J., Atmos. Sci., 41(1984), 156- 158.

[ 5 ] Preuss, H. J. et al., Arch. Met. Geoph. Biokl, Ser. A. 29(1981), 345-356.

[6] ZZhong Qiang et al., Advances, in Atmospheric Sciences, 5(1988). 57-65.

[7] 钟强、吴士杰,高原气象,4(1985), 193-203.

[ 8 ] Paltridge, G. W. et al., Developments in Atmospheric Science, Elsevier Scientific Publishing Co., 5(1976), 318.

[ 9 ] Katherine, B. K., NOAA Polar Orbiter Data Users Guide, U. S. Department of Commerce, Dec. 1986, 2-2-3-4.

[10] Thekaekara, M. P., Appl. Opt., 15(1976), 915-920.

[11] Gutman, G., J. Appl. Meteor, 27(1988), 973-988. 